\title{
Linear Periodization and Non Liner Periodization: Which Is Better?
}

\author{
Oktav Matakupan; Firmansyah Dlis; Johansyah Lubis; Iman Sulaiman \\ Fakultas Ilmu Olahraga, Univeritas Negeri Jakarta, Indonesia
}

http://dx.doi.org/10.18415/ijmmu.v8i1.2306

\begin{abstract}
Choosing the right training method is one of the elements of a coach's success in increasing athlete's performance. This study aims to test the linear periodization training method and the non-linear periodization training method. The method used in this determination is This experimental research used a $2 \times 2$ factorial design. The research design takes into account the possibility of a moderating variable affecting the treatment (independent variable) on the outcome (dependent variable). In this study, there are two methods of hockey training, namely the group that exercises using linear periodization and the group that uses non-linear periodization. This research was conducted for 16 meetings with an intensity of 60 minutes per meeting. The subjects studied were UNJ hockey athletes. The results of this study indicate that the non-linear periodization training method is more effective for increasing leg muscle strength.
\end{abstract}

Keywords: Hockey; Linear Periodization and Non Liner Periodization

\section{Introduction}

The achievements of Indonesian sports in the last 10 years have not developed according to the expectations of its lovers (Aziz, A.R., Chuan, 2004) . This is evident in the 5 times the Multy Sports Event in Southeast Asia (SEA games / SG) has always held a less honorable position even though it was in the first position at SG 2011 Jakarta. The results of field observations as the monitoring team of the Indonesian Sports Committee found errors in implementing the Periodization model variations by almost all coaches in various sports (Gomes De Araujo, Manchado-Gobatto, Papoti, Camargo, \& Gobatto, 2014), even though the correct application of periodization is essential in pursuing achievement. All the training variables above are usually programmed according to one of the most important developments in the technology of sport training that is periodization of training (Pavlović, Idrizović, \& Pupiš, 2015).

Mistakes in choosing a training periodization model will have fatal consequences in the world of sports achievements(Queiroga et al., 2013)(CASTAGNA et al., 2010). So that the timing and emphasis in their daily programs will have a huge impact on improving the athlete's own performance. Where together we know that the peak of achievement is designed well in the span of 4 years - 1 year and even the achievement of achievements in a matter of months really depends on the type / characteristics of the sport (sports) and athletes and the natural conditions around them. The desire to be able to demonstrate the best performance at the desired time, is one of the rationale that underlies the terminology of planning 
and organizing training stages. Driven also by the awareness that it is impossible throughout the year an athlete is always in peak condition (Hoffman, Epstein, Einbinder, \& Weinstein, 1999).

Returning the sporting achievements to a minimum that was victorious in Southeast Asia as it was $10-15$ years ago is not an impossible task for this great Indonesian nation. That we have been victorious to the ASIA level is a fact, which has a big meaning that mentally we have a winning mentality which means that we are a nation of warriors who have a good work ethic to achieve better achievements(Marcelino et al., 2016).

By conducting this research, we hope that sports coaches in Indonesia will have knowledge of the existing periodization models in the world and they can choose to sort out which periodization model principles are suitable for them to apply to their sport. By choosing the right periodization model, and of course if you are lucky to be able to work with everyone around you to create a good environment of excellence, then all the designs in the Periodization Model you choose can be carried out as well as possible.

The submission of the periodization model which is not commonly used in the achievement sports environment in Indonesia. Apart from the renewal form of this research, it is hoped that the trainers in Indonesia will not only become the coaches who are usually called mr. down load. Where after downloading the load - learn a little (skin), then immediately say this is the newest and best periodization model. Even though it has not been studied in depth whether it fits the sports situation in Indonesia - it fits the culture of the Indonesian people - whether it fits the climate in Indonesia.

Of course, with this research example, it is hoped that the trainers in Indonesia will be more careful in applying a science, especially if they must be held accountable for being a human with the consequences of their achievement.

Using periodization can vary the program either within a week (non linear or undulating periodization, UP). The linear model is the most classic model of periodization with thraining emphazing a strength component over o few weeks before changing to another component.

\section{Methods}

This research is a quasi-experimental research. In general, this study aims to compare the results of linear and non-linear periodization exercises on the increase in leg muscle strength in UNJ hockey athletes. Social studies using audiovisual media and pictorial concept cards with the control variable is the student's learning style.

This experimental research used a $2 \times 2$ factorial design. The research design takes into account the possibility of a moderating variable affecting the treatment (independent variable) on the outcome (dependent variable). In this study, there are two methods of hockey training, namely the group that exercises using linear periodization and the group that uses non-linear periodization. This research was conducted for 16 meetings with an intensity of 60 minutes per meeting. The subjects studied were UNJ hockey athletes. 


\section{Result and Discussion}

The research data were grouped into four groups of data, namely: (1) non-linear model initial test score $\left(\mathrm{Y}_{1}\right),(2)$ non-linear model final test score ( $\left.\mathrm{Y}_{12}\right),(3)$ linear model initial test score $\left(\mathrm{Y}_{21}\right)$, and (4) the final linear model test score $\left(\mathrm{Y}_{22}\right)$. Complete descriptions of the four data groups are as follows:

\section{Non Linear Model Initial Test Score ( $\left.\mathbf{Y}_{11}\right)$}

Based on the data collected from 20 respondents, it is known that the non-linear model pre-test score data obtained the highest score of 300; and the lowest score is 216; the average value is 261.50; median value 260; mode value 240; variance 670.89; and standard deviation of 25.90. Furthermore, the summary of the non-linear model initial test score data description is arranged in the frequency distribution table as follows:

Table 1.Data Frequency Distribution $Y_{11}$

\begin{tabular}{|c|c|c|c|c|c|c|c|}
\hline \multirow{2}{*}{ No. } & \multirow{2}{*}{\multicolumn{2}{|c|}{ Interval Class }} & \multicolumn{2}{|l|}{ Limit } & \multicolumn{3}{|c|}{ Frequency } \\
\hline & & & Under & On & Absolute & Cumulative & Relatively \\
\hline 1 & 216 & 232 & 215.5 & 232.5 & 3 & 3 & $15.00 \%$ \\
\hline 2 & 233 & 249 & 232.5 & 249.5 & 5 & 8 & $25.00 \%$ \\
\hline 3 & 250 & 266 & 249.5 & 266.5 & 3 & 11 & $15.00 \%$ \\
\hline 4 & 267 & 283 & 266.5 & 283.5 & 5 & 16 & $25.00 \%$ \\
\hline \multirow[t]{2}{*}{5} & 284 & 300 & 283.5 & 300.5 & 4 & 20 & $20.00 \%$ \\
\hline & & & & & 20 & & $100 \%$ \\
\hline
\end{tabular}

The frequency distribution of the non-linear initial test scores in table 1 can be presented in the following histogram graph:

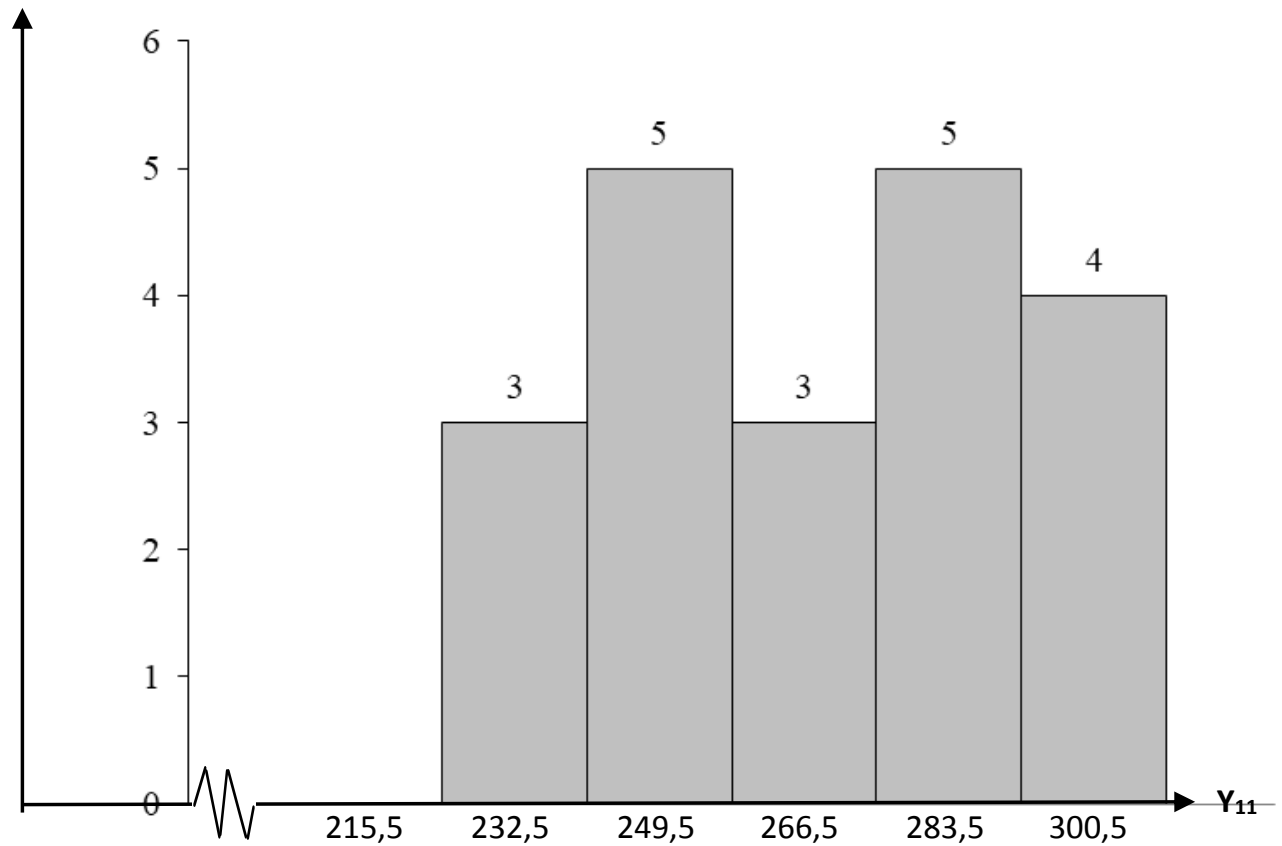

Figure 1 Graph of Y Data Histogram 


\section{Non Linear Model Final Test Score ( $\left.\mathbf{Y}_{12}\right)$}

Based on the data collected from 20 respondents, it is known that the final non-linear model test score data obtained the highest score 390; and the lowest score of 270; average value 328.50; median value 330; mode value 350; variance 831.84 ; standard deviation of 28.84 . Furthermore, the summary of the final non-linear model test score data description is arranged in the frequency distribution table as follows:

Table 2 Data Frequency Distribution $\mathrm{Y}_{12}$

\begin{tabular}{|c|c|c|c|c|c|c|c|}
\hline \multirow{2}{*}{ No. } & \multirow{2}{*}{\multicolumn{2}{|c|}{ Interval Class }} & \multicolumn{2}{|l|}{ Limit } & \multicolumn{3}{|c|}{ Frequency } \\
\hline & & & Under & On & Absolute & Cumulative & Relatively \\
\hline 1 & 270 & 293 & 269.5 & 293.5 & 2 & 2 & $10.00 \%$ \\
\hline 2 & 294 & 317 & 293.5 & 317.5 & 4 & 6 & $20.00 \%$ \\
\hline 3 & 318 & 341 & 317.5 & 341.5 & 7 & 13 & $35.00 \%$ \\
\hline 4 & 342 & 365 & 341.5 & 365.5 & 6 & 19 & $30.00 \%$ \\
\hline \multirow[t]{2}{*}{5} & 366 & 390 & 365.5 & 390.5 & 1 & 20 & $5.00 \%$ \\
\hline & & & & & 20 & & $100 \%$ \\
\hline
\end{tabular}

The frequency distribution of the final non-linear model test scores in table 2 can be presented in the following histogram graph:

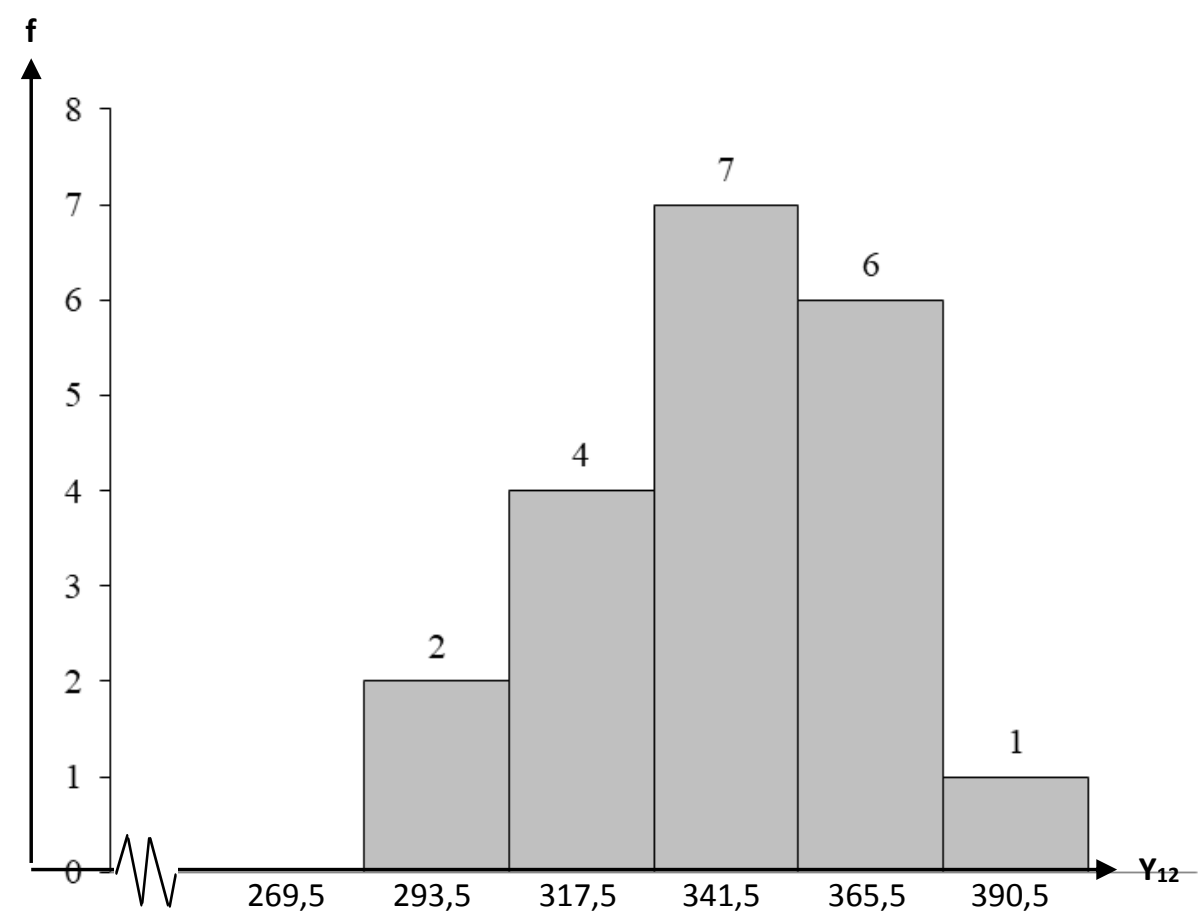

Figure 2 Graph of Y Data Histogram 12

\section{Linear Model Initial Test Score $\left(\mathbf{Y}_{21}\right)$}

Based on the data collected from 20 respondents, it is known that the initial linear model test score data obtained the highest score of 272; and the lowest score is 160; an average value of 200.25; 
median value 195; mode value 180; variance 974.20; and standard deviation 31.21. Furthermore, the summary of the data description of the initial linear model test score is arranged in the frequency distribution table as follows:

Table 3 Distribution of Y Data Frequency 21

\begin{tabular}{|c|c|c|c|c|c|c|c|}
\hline \multirow{2}{*}{ No. } & \multirow{2}{*}{\multicolumn{2}{|c|}{ Interval Class }} & \multicolumn{2}{|l|}{ Limit } & \multicolumn{3}{|c|}{ Frequency } \\
\hline & & & Under & On & Absolute & Cumulative & Relatively \\
\hline 1 & 160 & 182 & 159.5 & 182.5 & 9 & 9 & $45.00 \%$ \\
\hline 2 & 183 & 205 & 182.5 & 205.5 & 4 & 13 & $20.00 \%$ \\
\hline 3 & 206 & 228 & 205.5 & 228.5 & 2 & 15 & $10.00 \%$ \\
\hline 4 & 229 & 251 & 228.5 & 251.5 & 4 & 19 & $20.00 \%$ \\
\hline \multirow[t]{2}{*}{5} & 252 & 274 & 251.5 & 274.5 & 1 & 20 & $5.00 \%$ \\
\hline & & & & & 20 & & $100 \%$ \\
\hline
\end{tabular}

The frequency distribution of the initial linear model test scores in table 3 can be presented in the form of the following histogram graph:

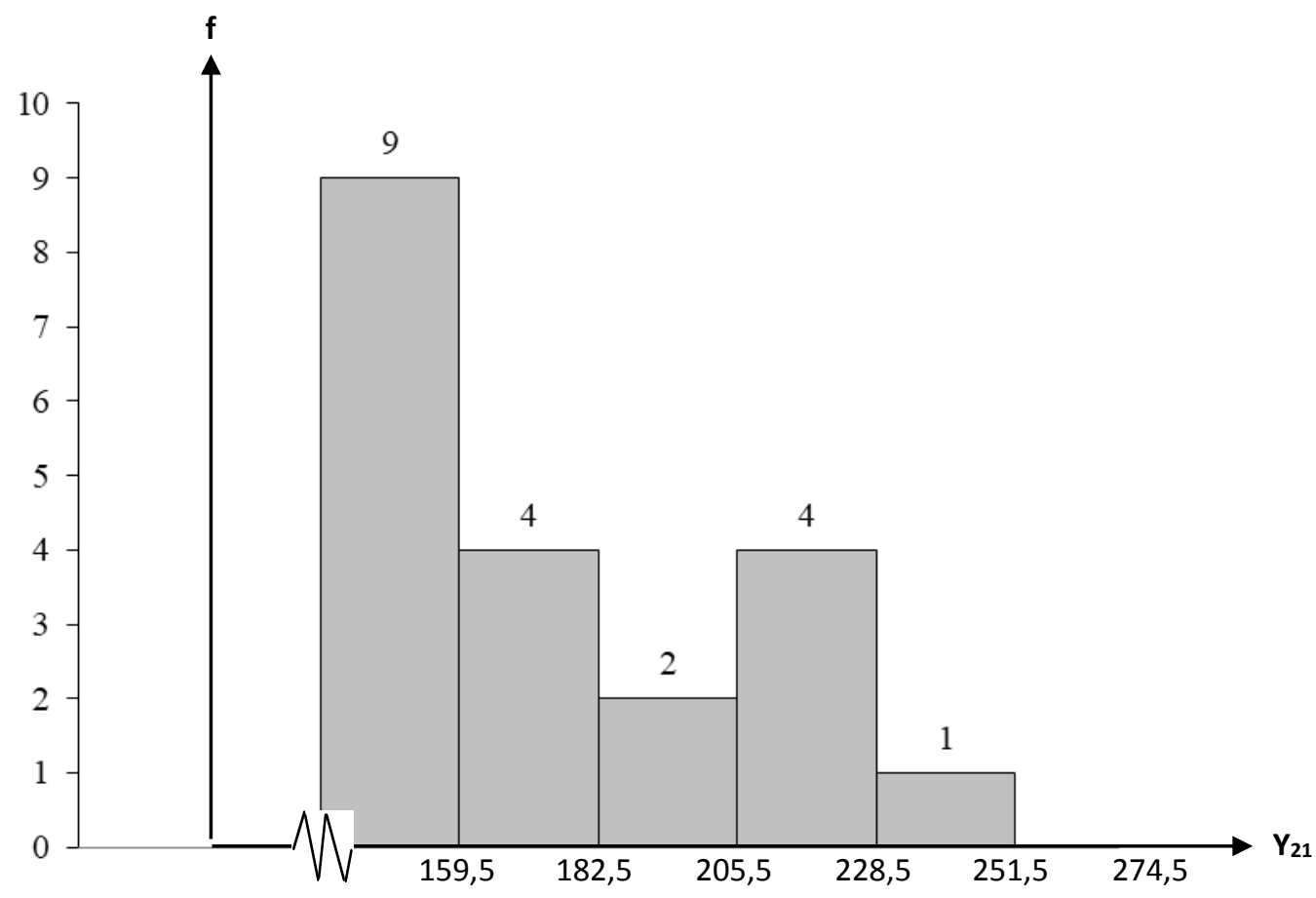

Figure 3 Graph Y ${ }_{21}$ Histogram Data

\section{Linear Model Final Test Score ( $\left.\mathbf{Y}_{22}\right)$}

Based on the data collected from 20 respondents, it is known that the final linear model test score data obtained the highest score of 300; and the lowest score of 170; average value 232.50; median value 230; mode value 300; variance 2711.84; standard deviation of 52.08. Furthermore, the summary of the final linear model test score data description is arranged in the frequency distribution table as follows: 
Table 4 Distribution of Y Data Frequency 22

\begin{tabular}{|c|c|c|c|c|c|c|c|}
\hline \multirow{2}{*}{ No. } & \multirow{2}{*}{\multicolumn{2}{|c|}{ Interval Class }} & \multicolumn{2}{|l|}{ Limit } & \multicolumn{3}{|c|}{ Frequency } \\
\hline & & & Under & On & Absolute & Cumulative & Relatively \\
\hline 1 & 170 & 195 & 169.5 & 195.5 & 9 & 9 & $45.00 \%$ \\
\hline 2 & 196 & - 221 & 195.5 & 221.5 & 0 & 9 & $0.00 \%$ \\
\hline 3 & 222 & 247 & 221.5 & 247.5 & 2 & 11 & $10.00 \%$ \\
\hline 4 & 248 & 273 & 247.5 & 273.5 & 3 & 14 & $15.00 \%$ \\
\hline \multirow[t]{2}{*}{5} & 274 & 300 & 273.5 & 300.5 & 6 & 20 & $30.00 \%$ \\
\hline & & & & & 20 & & $100 \%$ \\
\hline
\end{tabular}

The frequency distribution of the final linear model test scores in table 4 can be presented in the following histogram graph:

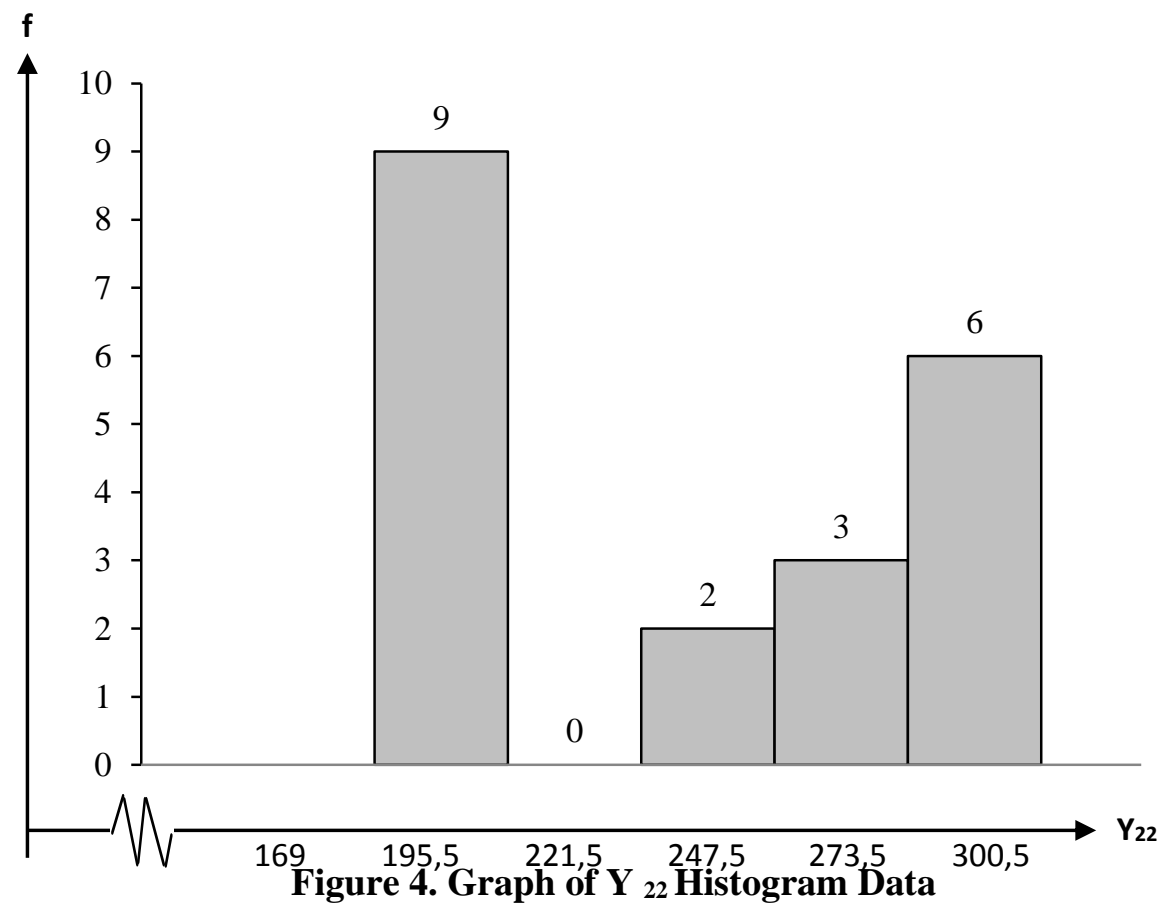

\section{Discussion}

\section{Differences in Non Linear Modal Test Results}

Based on the calculation results at the significance level $\alpha=0.05$, it is obtained $t_{\text {count }}=12,46$ and $\mathrm{t}_{\text {table }}=1,73$. Thus $\mathrm{t}_{\text {count }}>\mathrm{t}_{\text {table }}$, so that $\mathrm{H}_{0}$ is rejected, it can be concluded that there is a significant difference in the non-linear model test scores . In other words, that the average score tests early non-linear models $\left(\bar{Y}_{11}=261,50\right)$ is lower than the average score of the final test non-linear models $\left(\bar{Y}_{12}=328,50\right)$. This means that the research hypothesis which states that there is a difference between the pre-test and the non-linear model's final test is acceptable.

\section{Differences in the Linear Modal Test Results}

Based on the results of the calculation of the significant level $\alpha=0.05$, obtained $t_{\text {count }}=5,68$ and $t_{\text {table }}=1,73$. Thus $t_{\text {count }}>t_{\text {table }}$, so that $\mathrm{H}_{0 \text { is }}$ rejected, it can be concluded that there is a significant difference in the results of the linear model test. In other words, that the average scores of initial tests of linear models $\left(\bar{Y}_{21}=200,25\right)$ is lower than the average score of the final test of linear models $\left(\bar{Y}_{22}=232\right.$, 
50). This means that the research hypothesis which states that there is a difference between the initial test and the final test of the linear model is acceptable.

\section{Difference in Final Test Results Between Non Linear Model $\left(\mathbf{Y}_{12}\right)$ and Linear Model $\left(\mathbf{Y}_{22}\right)$}

Based on the results of calculations at the significant level $\alpha=0.05$, it is obtained $t_{\text {count }}=5,22$ and $\mathrm{t}_{\text {table }}=1,69$. Den gan so $\mathrm{t}_{\text {count }}>\mathrm{t}$ table, so that $\mathrm{H}_{0}$ is rejected, it can be concluded that there is a difference between the final test results of non linear models and linear models. In other words, the nonlinear model $\left(\bar{Y}_{12}=328,50\right)$ is better than the linear model $\left(\bar{Y}_{22}=232,50\right)$. This means that the research hypothesis which states that the final non-linear model test is significantly higher than the final linear model test is acceptable.

\section{References}

Aziz, A.R., Chuan, T. E. H. K. (2004). Correlation between tests of running repeated sprint ability and anaerobic capacity by Wingate cycling in multi-sprint sports athletes. International Journal of Applied Sports Sciences, 16(1), 14-22.

CASTAGNA, C., MANZI, V., IMPELlIZZERI, F., CHAOUACHI, A., ABDELKRIM, N. BEN, \& DITROILO, M. (2010). V o -c 1 t t y b p, (16), 2434-2439.

Gomes De Araujo, G., Manchado-Gobatto, F. D. B., Papoti, M., Camargo, B. H. F., \& Gobatto, C. A. (2014). Anaerobic and aerobic performances in elite basketball players. Journal of Human Kinetics, 42(1), 137-147. https://doi.org/10.2478/hukin-2014-0068

Hoffman, J. R., Epstein, S., Einbinder, M., \& Weinstein, Y. (1999). The Influence of Aerobic Capacity on Anaerobic Performance and Recovery Indices in Basketball Players. Journal of Strength and Conditioning Research, 13(4), 407-411. https://doi.org/10.1519/15334287(1999)013<0407:TIOACO>2.0.CO;2

Marcelino, P. R., Aoki, M. S., Arruda, A. F. S., Freitas, C. G., Villanueva, M., \& Moreira, A. (2016). Does small-sided-games' court area influence metabolic, perceptual, and physical performance parameters of young elite basketball players? Biology of Sport, 33(1), 37-42. https://doi.org/10.5604/20831862.1180174

Pavlović, R., Idrizović, K., \& Pupiš, M. (2015). Evaluation of anaerobic abilities of students applying the running anaerobic sprint test. Sport Scientific and Practical Aspects, 12(2), 23-31.

Queiroga, M. R., Cavazzotto, T. G., Katayama, K. Y., Portela, B. S., Tartaruga, M. P., \& Ferreira, S. A. (2013). Validity of the RAST for evaluating anaerobic power performance as compared to wingate test in cycling athletes. Motriz. Revista de Educacao Fisica, 19(4), 696-702. https://doi.org/10.1590/S1980-65742013000400005

\section{Copyrights}

Copyright for this article is retained by the author(s), with first publication rights granted to the journal.

This is an open-access article distributed under the terms and conditions of the Creative Commons Attribution license (http://creativecommons.org/licenses/by/4.0/). 